\title{
Pulmonary Rehabilitation in lung cancer
}

\author{
F. Pasqua1', K. Geraneo1, I. Nardi1, F. Lococo², A. Cesario3
}

ABSTRACT: Pulmonary Rehabilitation in lung cancer. F. Pasqua, K. Geraneo, I. Nardi, F. Lococo, A. Cesario.

Non-small-cell lung cancer (NSCLC) represents a very severe disease, being its incidence increasingly reported and, nowadays, successfully treatable only when surgery is deemed to be feasible. Furthermore, the disease and the clinical effects related to the complementary therapies (radio and/or chemotherapy) may strongly affect, frequently with dramatic clinical side effects, the patient's ability to endure physical exercise. In such context, the PR(PR), which has already been proved to be useful and effective in other diseases such as COPD, could play a pivotal role.
The aim of this review article is, therefore, to analyze the pertinent data recently reported in English literature in order to highlight the role of rehabilitation as complementary therapy in the management of patients with NSCLC.

The evidence currently available suggests that, when surgery is indicated, $P R$ is a safe and feasible option, both during pre-operative and post-operative timing.The safety and feasibility of rehabilitation are proven even in inoperable patients, although to date, little evidence has been reported on its role in the overall management of such complex diseases.

Monaldi Arch Chest Dis 2013; 79: 2, 73-80.

Keywords: Pulmonary rehabilitation, Lung cancer, Surgery.

1 Department of Pulmonary Rehabilitation, IRCCS San Raffaele Pisana, SR Montecompatri Unit, Rome;

2 Unit of Thoracic Surgery, IRCCS Arcispedale Santa Maria Nuova, Reggio Emilia;

3 Deputy Scientific Director, IRCCS San Raffaele Pisana, Rome, Italy.

Correspondence: Franco Pasqua, IRCCS San Raffaele Pisana, Rome, Italy; e mail: franco.pasqua@sanraffaele.it

\section{Introduction}

Pulmonary Rehabilitation (PR) is based on a multidisciplinary tailored approach designed to improve exercise capacity, functional status, quality of life, and to reduce symptoms such as dyspnea and fatigue.

These objectives may be achieved through training exercises, psychosocial interventions, behavior modification and, above all, significant "compliance" to the PR protocol by the patient in his or her social environment. The effectiveness of PR in patients with Chronic Obstructive Pulmonary Disease (COPD) is an unmistakable footprint and based on scientific evidence. As a consequence evidence suggests that, in the recent years, PR has been commonly adopted into the overall management of such patients.

Moreover, its efficacy has been tried and tested for diseases other than COPD [1] such as Non Small Cell Lung Cancer (NSCLC), considering that these patients present comparable patterns of impairment in respiratory function and similar symptoms to those of patients with COPD; accordingly, an increasing interest is aimed at patients with NSCLC.

NSCLC is one of the most common of all lung diseases: every year more than 1.6 million diagnosis of NSCLC are made worldwide and this number is expected to rise in the near future [2]; mortality in such patients is still very high in the absence of therapy [2]; on the other hand, evidence suggests that patients receiving the appro- priate treatment, especially if the disease is diagnosed at an early stage, have a more improved prognosis $[3,4]$.

The increasing proportion of patients who underwent radio and/or chemotherapy and scheduled for surgical resection (or already surgically treated) has given rise to problems related to long-term morbidity, which has a direct impact on the social and economic "background" of such patients [5]. In fact, patients affected by NSCLC present symptoms such as breathlessness and muscle fatigue $[6,7]$, that negatively influences quality of life, functional status and daily live activities [8-14]. England [15] also found that the factor most strongly correlated with exercise capacity in NSCLC patients was "muscle strength".

If we also consider the effects of certain therapies, we may get a better understanding that exercise tolerance in such patients is greatly compromised [16-19].

Another crucial aspect is the frequent relationship between NSCLC and COPD: in an epidemiological study [20], COPD occurs in $73 \%$ of men and $53 \%$ of women with NSCLC. Recent studies also show that physical performance is an independent predictor of survival in NSCLC patients [21-23], currently the same goes for depression and anxiety which usually accompanies the disease [24].

In light of these considerations, it's clear that there is a growing interest in the identification of strategies to enable patients suffering from NSCLC to improve exercise tolerance, anxiety and 
depression, which are the main factors involved in the decline in their quality of life; in this scenario, PR with specific muscular exercises may play a decisive role [25-27]. This review is intended to analyze the most recent literature: in recent years, in fact, many articles have reported on the potential role of PR in the management of patients with not-operable NSCLC; although the evidence regarding its efficacy on symptoms has not been proven yet, the general impression that emerges is that respiratory exercises represent a valid and useful strategy to adopt in the overall management of these patients.

Our analysis has been divided into the following chapters:

1. Functional assessment of patients with lung cancer

2. PR as "preventive" treatment

3. PR for non-operable patients:

- PR for terminal patients ("palliative support")

- PR for patients undergoing chemotherapy and/or radiotherapy

4. PR for surgical patients:

- Evaluation of preoperative respiratory function

- Preoperative Rehabilitation

- Postoperative Rehabilitation

\section{Functional Assessment}

This plays a key-role but only from the workup diagnostic evaluation. Currently, for this purpose, the scale of Karnovsky [28] or the Eastern Cooperative Oncology Group performance status (ECOG) [29] is widely adopted in clinical practice being that they help to predict the long-term survival of NSCLC patients. Nevertheless, they often suffer from excessive subjectivity and also do not accurately express the functional capacity, especially of those subjects with other comorbidities, the latter significantly influences the assessment of the quality of life and, ultimately, the prognosis.

The use of methods capable of accurately assessing the functional capacity, therefore plays an important role in the planning of a personalized therapeutic program. As already remarked, in fact, NSCLC patients usually presented symptoms similar to those related to COPD such as dyspnea, reduced exercise capacity, respiratory distress and a deteriorated quality of life. However, while in COPD have been well identified anatomical, physiological and biochemical alterations that are the basis of muscular dysfunction, as well as the biological mechanisms that may be the cause, namely the inactivity, the use of corticosteroids, systemic inflammation and oxidative stress $[30,31]$, this has not yet occurred in cancer patients.

However, it appears clear that, in NSCLC patients, exercise capacity is greatly reduced: Jones reported that in these subjects, the mean peak $\mathrm{VO}_{2}$ was $33 \%$ that of predicted [32], concluding that the Cardiopulmonary Exercise Test (CPET) represents an accurate parameter in evaluating the fitness of selected patients with NSCLC. The same author has subsequently shown that the reduction in exercise capacity is a strong predictor of mortality, which is regarded as the $\mathrm{VO}_{2}$ peak [33], or the MET'S products or meters walked to the walk test [34].

Nevertheless, the clinical significance of this data is currently not well defined: to date, in fact, there are few studies which demonstrate, with any degree of certainty, the feasibility, safety and efficacy of a program of exercise training in patients with unresectable NSCLC, while COPD patients derive remarkable benefits from pulmonary rehabilitation.

Thus, we believe that despite the scarcity of pertinent data available in the literature, the evaluation of exercise capacity is pivotal in the management of patients with NSCLC, both for prognostic and therapeutic reasons.

\section{Rehabilitation and prevention}

Many epidemiological studies have attempted to investigate the possible correlation between physical exercise and cancer prevention: the main conclusions emerging from these studies tend to support the hypothesis that with regard to certain forms of cancer, physical activity is associated with reduced incidences of cancer; for example, subjects with a more active lifestyle have reduced the relative risk of colon cancer by as much as $30-40 \%$ and breast cancer by $20-30 \%$, when compared to a similar sedentary population [35]. The mechanisms behind this phenomenon are yet unclear. Contrarily, there are few studies regarding the possible preventive action exercise has on the occurrence of lung cancer; Steindorf [36], produced a very extensive series reporting the lack of protective effects of exercise on the risk of cancer, and the International Agency for Research on Cancer (IARC) concluded, in 2002, the lack of evidence regarding the effectiveness of physical activity in reducing the risk of lung cancer [37]. To summarise our opinion, currently, there is no scientific evidence to support or at least suggest the effectiveness of exercise in reducing the incidence of lung cancer.

\section{Rehabilitation on inoperable patients}

Most cancer patients (approximately 75\%) at the time of diagnosis are inoperable and often with reduced exercise capacities; very often a number of comorbidities can be present. As an example, cardiovascular comorbidities can further limit exercise capacity, limitation which can be aggravated even further by radio and/or chemotherapy treatment, as well as by the concomitant supportive therapies; biological or corticosteroid which can, on the other hand, increase the risk of adverse events related to physical activity.

\section{Rehabilitation in patients with advanced cancer (palliative rehabilitation)}

In patients with advanced stages of disease, much emphasis has been given to the control of 
symptoms and pain management, with very little emphasis given to the improvement of physical activity: neverthless, there is increasing evidence, although often concerning other tumors, which suggest that as rehabilitation intervention is safe, costeffective and extremely useful in improving functional independence and overall quality of life of cancer sufferers [38-43]. In the series by Morris and co-workers [44], not only solid tumors (among them not only NSCLC) but also hematological malignancies are included; the Authors concluded that an aerobic exercise program determined significant improvements in exercise tolerance; moreover, in a randomized clinical trial carried out by Cheville [45], patients with advanced stages of lung cancer and colorectal cancer were enrolled and underwent home training regimens: results showed improvements in exercise tolerance and quality of life, although very often worsening of the disease can lead to a high dropout rate [46]; finally a recent meta-analysis performed by Jones et al [47], examined six randomized trials within a controlled group (a total 571 patients with breast or prostate cancers or lymphomas), and found that anaerobic training programs may produce a significant increase in $\mathrm{VO}_{2}$ peak, without any major adverse events. Based on these studies, our opinion is that when feasible, a structured program of aerobic exercise training should always be offered to patients with lung cancer, as a safe and effective method in improving physical performance and quality of life; therefore, it should become part of the overall management of these patients with the same relevance given to the symptoms and pain control.

\section{Rehabilitation on patients undergoing chemo and/or radiotherapy treatment}

As already remarked, chemo and radiation therapy, usually administered with radical intent, in addition to worsening the symptoms and quality of life, may lead to - (among the various adverse events) - pulmonary toxicity. Marks et al [48] reported that dyspnea after radiation therapy is present in about $5 \%$ of all patients receiving "localized" and "regional" radiation therapy, with or without combined chemotherapy. The negative side effects of chemotherapy on exercise capacity are not well investigated, although it is known that platinum-based regimens may cause anemia and a reduction in functional parameters, especially $\mathrm{FEV}_{1}$. While the latter parameter seems to be not uncorrelated with exercise capacity [49], the reduction of hemoglobin can determine a significant reduction in the release of $\mathrm{O}_{2}$ with a consequential decrease of the $\mathrm{VO}_{2}$-peak. Lung cancer patients are usually elderly, smokers with underlying comorbidities such as COPD and ischaemic heart disease, which may further decrease cardiorespiratory fitness. In the past, several studies have attempted to analyze the effects of exercise as a supportive therapy in mitigating fatigue and physical decline induced by chemo and radiation therapy on women with breast cancer. Several systematic re- views and meta-analysis have concluded that exercise training, whether it be aerobic exercise alone or combined with anaerobic training, result in significant positive effects on fitness levels, Quality of Life (QoL), anxiety, depression, and exercise tolerance [50]. Even in this case, some case studies enrolled a non-homogeneous sample population; Adamsen [51], for example, has found, in a group of subjects suffering from lung and breast cancer, not only significant improvements in $\mathrm{O}_{2-}$ Peak-max and muscle strength, but also an increase in the time dedicated to physical activities rather than sedentary time. Positive effects have also been reported by prospective studies [52-54]. A recent randomized study demonstrated the efficacy of aerobic exercise in improving exercise capacity in a group of patients with adenocarcinoma and receiving targeted chemotherapy [55]. And finally, another recent study, albeit limited by the dimension of the small series, observed that an intensive rehabilitation protocol is capable of cancelling the toxic effects on lung functioning and QoL induced by radio/chemotherapy [56]. In summary we believe that to date there is little evidence to support the use of rehabilitation on inoperable lung cancer patients undergoing medical and/or radiation therapy. However, the efficacy demonstrated in other types of cancer and its security, lead one to consider the opportunity to integrate it into the overall management program of the disease.

\section{Rehabilitation for operable patients}

\section{Pre-operative functional evaluation}

Pre-operative functional evaluation is deemed necessary for all types of cancer, therefore it is pivotal if not indispensable for those considered operable. Respiratory function assessment is obviously very important, especially for COPD patients: for example, it has been established that the diffusion of carbon monoxide represents an important parameter in predicting post-operative complications in patients with $\mathrm{FEV}_{1}$ within the ranges [57-58], and at the same time the physician should not ignore the assessment of exercise capacity. The latter has been proven to be inversely correlated with post-operative morbidity and mortality, as shown by several studies [59-60], including a recent meta-analysis of 955 patients [61], and finally by the guidelines laid down by the ERS / ESTS Joint Task Force [62].

Also the pre-operative QoL is a factor which helps predict survival probability [63]. A careful multidimensional evaluation is therefore essential, not only as it is an eligibility criterion for surgical planning, but also for the prognostic stratification. In this context, among all the possible physiological assessments, a symptom-limited incremental test with analysis of expired gases, more commonly called CPET, is, as already mentioned above, the Gold Standard [64-66]; thus, among the various available parameters, the slope of the ratio of minute ventilation $/ \mathrm{CO}_{2}$ output $\left(\mathrm{VE} / \mathrm{CO}_{2}\right)$, which represents ventilatory ineffi- 
ciency, is the strongest predictor of post-operative complications and mortality $[67,68]$. In recent years it has been cited in scientific literature as the Stair-Climbing Test, which has been proven by several studies (based on an extensive series) to play an important role in predicting complications after lung resection. The advantages when compared with the classic CPET are, in addition to the simplicity, low cost (it requires little or no equipment and personnel), safety, user-friendliness for patients and the involvement of a greater number of muscle groups with respect to the cycle ergometer or treadmill. It has also been demonstrated that this test may determine higher levels of oxygen consumption, compared with a treadmill or cycle ergometer, therefore it seems more suitable in highlighting oxygen transfer deficiency which could cause post-operative complications or mortality [69-72].

\section{Pre-surgical Rehabilitation}

Surgical exeresis is still the treatment of choice for thoracic malignancies with limited extension: however, only $25 \%$ of such tumors at the time of diagnosis were considered operable. Among the causes of inoperability, the poor respiratory status accounts for approximately $40 \%$ of cases [73]. Surgery also causes a further reduction in exercise capacity which is proportional to the extent of resection $[74,75]$. Such a reduction persists for anything up to three years after surgery, while still remaining lower than pre-operative values [74]. In light of these findings, a series of respiratory rehabilitation exercise prior to surgery can be conducted with a couple of aims in mind: firstly to increase the percentage of operable cases; secondly, to reduce the consequences of the intervention, both in terms of mortality and morbidity. To date, however, there is no convincing scientific data to recommend the use of pre-operative rehabilitation for lung cancer patients: This can be due (at least in part) to the fact that the time between diagnosis and surgery is generally very short, and therefore does not allow for patients to participate in a standard program of rehabilitation: a study by Boczuk [76], however, shows that a delay up to 48 days of surgical treatment, does not influence the overall survival rate.

Some studies have demonstrated that a training aerobic program is capable of significantly inproving not only oxygen consumption but also performance during the walking-test and overall QoL [77, 78]; similarly Bobbio et al have investigated the oxygen consumption effects during a fourweek rehabilitation program carried out on a group of 12 COPD patient with NSCLC candidates for lobectomy. The program included a total of 20 sessions, diaphragmatic breathing exercises and a combined aerobic and strength training. The results showed a significant increase in $\mathrm{VO}_{2}$-peak, anaerobic threshold and maximum load reached in the incremental exercise test [79]. More recently, the data analysis of a randomized controlled trial shows that patients who performed a pre-operative
PR program, including aerobic and anaerobic training, experienced lower numbers of post-operative complications, therefore resulting in a reduction in hospital stays, when compared with a control group, which performed simple exercises for lung expansion [80]. The results of these studies show that a quick program of PR performed prior to surgery may induce significant improvements in exercise capacity on patients undergoing surgery for lung cancer. This data may have relevant clinical implications, among which the most conclusive being that pre-operative exercise training may increase the number of patients who, after rehabilitation, can undergo surgical exeresis of lung cancer. In this setting, there is a very interesting study which evaluates a small group of patients declared ineligible for surgery, not because of the staging, but due to poor functional pulmonary conditions: after 20 sessions of a rehabilitation program (consisting of training of the lower limbs by cycle ergometer, technical diaphragmatic relaxation and educational support), all patients meet the criteria of operability and were thus surgically treated successfully [81].

Thus, our opinion is that PR should always be recommended during the pre-operative management of these patients, as it seems to improve exercise capacity and consequently reduce the postoperative morbidity and mortality rate. Moreover preliminary evidence suggests its effectiveness in increasing the number of cases judged "technically operable".

\section{Post-surgical Rehabilitation}

As we have repeatedly emphasized, surgery is the most important treatment option for lung cancer patients, as it represents the only curative intervention. However, the effects on the functional capacity are clearly relevant: it has been estimated that the $\mathrm{VO}_{2}$-peak decreases by approximately $30 \%$ after pneumonectomy and $20 \%$ after lobectomy; in addition this reduction seems to persist for anything up to three years after resection, and even after recovery time, it stood at a lower value than before the intervention $[74,75]$. The mechanisms involved may be different than the extent of resection but we should take into account that about half of patients after undergoing surgery receive post-operative adjuvant therapy, the latter producing, as already mentioned above, significant modification in their pulmonary functioning. In addition, many patients presented several comorbidities such as COPD or heart disease, and were either smokers or former smokers. All these factors contribute to muscle deconditioning, and ultimately to physical inactivity. There is evidence to suggest that, even in healthy subjects, a period of entrapment of about three weeks results in a $\mathrm{PO}_{2}$-peak reduction of about $25 \%$, this impacting on it more than the physiological decline caused by aging [82-84]. In light of that, the training exercise should play a key role in preventing or at least mitigating the harmful effects of surgery. Nevertheless, only a few 
Table 1. - Summary of the current evidences and possible indications for Pulmonary Rehabilitation in patients with lung cancer undergoing surgical resection

\begin{tabular}{|c|c|c|c|c|c|c|}
\hline & $\begin{array}{l}\text { Functional } \\
\text { Assessment of } \\
\text { patients with lung } \\
\text { cancer before surgery }\end{array}$ & $\begin{array}{l}\text { PR and prevention } \\
\text { of lung cancer }\end{array}$ & $\begin{array}{l}\text { PR in the inoperable } \\
\text { patient with } \\
\text { lung cancer }\end{array}$ & $\begin{array}{l}\text { PR in the patient } \\
\text { undergoing chemo } \\
\text { and/or radiotherapy } \\
\text { for lung cancer }\end{array}$ & $\begin{array}{l}\text { Pre-surgical PR } \\
\text { in patients with } \\
\text { lung cancer }\end{array}$ & $\begin{array}{l}\text { Post-surgical PR } \\
\text { in patients with } \\
\text { lung cancer }\end{array}$ \\
\hline References & $28-34$ & $35-37$ & $38-47$ & $48-56$ & $73-81$ & $74-75,82-87$ \\
\hline $\begin{array}{l}\text { Amount of } \\
\text { available data } \\
\text { and evidence }\end{array}$ & Little evidence & Not sufficient data & Sufficient data & Little evidence & Sufficient data & Limited data \\
\hline Key message & $\begin{array}{l}\text { Assessment of exercise } \\
\text { capacity is considered } \\
\text { pivotal in the } \\
\text { management of patients } \\
\text { with NSCLC, both } \\
\text { for prognostic and } \\
\text { therapeutic reasons }\end{array}$ & $\begin{array}{l}\text { PR and exercise } \\
\text { do not reduce the risk } \\
\text { of lung cancer }\end{array}$ & $\begin{array}{l}\text { PR is safe and effective } \\
\text { in improving physical } \\
\text { performance and quality } \\
\text { of life }\end{array}$ & $\begin{array}{l}\text { In analogy with patients } \\
\text { with other types } \\
\text { of cancer, patients } \\
\text { undergoing chemo } \\
\text { and/or radiotherapy } \\
\text { for lung cancer can be } \\
\text { prescribed PR }\end{array}$ & $\begin{array}{l}\text { It improves exercise } \\
\text { capacity, reduce the } \\
\text { postoperative morbidity } \\
\text { and mortality. It might } \\
\text { increase the number } \\
\text { of cases judged } \\
\text { "technically operable" }\end{array}$ & $\begin{array}{l}\text { PR after surgery } \\
\text { is safe and well } \\
\text { tolerated }\end{array}$ \\
\hline $\begin{array}{l}\text { Current possible } \\
\text { indications }\end{array}$ & $\begin{array}{l}\text { Assess exercise } \\
\text { capacity before } \\
\text { lung cancer surgery }\end{array}$ & There is no indication & $\begin{array}{l}\text { A structured program } \\
\text { of aerobic exercise } \\
\text { should be offered } \\
\text { to these patients }\end{array}$ & $\begin{array}{l}\text { It may be offered } \\
\text { to the patients }\end{array}$ & $\begin{array}{l}\text { PR before surgical } \\
\text { resection should be } \\
\text { offered to the patients }\end{array}$ & $\begin{array}{l}\text { PR after surgery } \\
\text { should be considered } \\
\text { in all patients who } \\
\text { have had lung resection }\end{array}$ \\
\hline
\end{tabular}

NSCLC = non-small cell lung cancer; PR = Pulmonary rehabilitation .

studies on this topic have been performed and are usually based on small patient numbers . During the first of these, Spruit et al investigated the effects of a multidisciplinary rehabilitation program conducted during hospitalization of 10 patients who recently underwent surgery for lung cancer. The program included, among other things, strength and endurance training . After 8 weeks a significant increase in distance was reported for the walk test which peaked during the incremental test [85]. Cesario et al have investigated the effects of a shorter program (4 weeks) of pulmonary in-patient rehabilitation treatment carried out on 25 patients undergoing lung resection; the rehabilitation program included a training cycle ergometer endurance, strength exercises and educational sessions. Compared with a group of patients who had refused the rehabilitation protocol, the distance during the walk test significantly increased, while there were no modifications in spirometry data [86]. Finally, Jones et al have evaluated the benefits of an aerobic training program in an outpatient regime of 20 post-surgical patients. The protocol consisted of 3 weekly sessions of a cycle ergometer for a period of 14 weeks. Exercise capacity was measured using the Peak $\mathrm{O}_{2}$ detected by an incremental CPET, QoL and muscle fatigue in the questionnaire FACT-L (Functional Assessment of Cancer Therapy-Lung). The results indicated a significant increase in maximal oxygen consumption and a significant improvement in QoL and muscle fatigue. A very interesting finding, although observed on only a small number of patients, consisted in the fact that the most significant im- provements were the prerogative of the patients who did not receive adjuvant chemotherapy [87]. To summarize, the limited literature on this topic indicates that rehabilitation after surgery is safe and well tolerated. It should therefore always be considered in all patients who have had lung resection.

\section{Conclusions}

The evidence available to date suggests that PR is safe and feasible in lung cancer patients, and that it can be administered in a variety of situations. In the terminal patient or those recovering from radio and/or chemotherapy, it has been proved to reduce symptoms (above all the dyspnea and fatigue) induced by the disease and therapy and at the same time improve overall QoL. The enhancement of functional capacity, on the other hand, may reduce the post-operative risks, especially after major lung resection. Furthermore, the optimization of the preoperative fitness obtained through a rehabilitation program, may make candidates for surgical resection those patients who, despite anatomical resectability, were declared inoperable due to poor physical performance. The planning of rehabilitation programs in the postoperative phase may lead to a reduction in recovery time after surgery and, accordingly, encourage a faster return to daily activities. To date there is no consensus on the right timing, duration and the components which should be part of the rehabilitation program. Studies adequately designed and several case studies are mandatory to clarify these aspects. 


\section{References}

1. Ries AL, Bauldoff GS, Carlin BW, et al. Pulmonary Rehabilitation: Joint ACCP/AACVPR Evidence-Based Clinical Practice Guidelines. Chest 2007 May; 131 (5 Suppl): 4S-42S.

2. Ferlay J, Shin HR, Bray F, et al. DM. GLOBOCAN 2008, Cancer Incidence and Mortality Worldwide: IARC Cancer Base No. 10. Lyon, France: International Agency for Research on Cancer; 2010.

3. Australian Institute of Health and Welfare \& Australasian Association of Cancer Registries AA. Cancer in Australia: an overview. Canberra: Australian Institute of Health and Welfare; 2008. No. CAN 42.

4. Australian Institute of Health, Welfare \& Australasian Association of Cancer Registries AA. Cancer survival in Australia, 2006. Part 1: national summary statistics. Canberra: Australian Institute of Health and Welfare; 2006.

5. Australian Bureau of Statistics A. Causes of death, Australia, 2004. Canberra: ABS; 2006 (cat. no. 3003.0).

6. Pujol JL, Quantin X, Chakra M. Cardiorespiratory fitness in patients with advanced non-small cell lung cancer: why is this feature important to evaluate? Can it be improved? J Thorac Oncol 2009; 4: 565-7.

7. Delgado-Guay MO, Parsons HA, Li Z, Palmer LJ, Bruera E. Symptom distress, interventions, and outcomes of intensive care unit cancer patients referred to a palliative care consult team. Cancer 2009 15; 115: 437-45.

8. Montazeri A, Hole MHD.Howquality of life data contributes to our understanding of cancer patients' experiences? A study of patients with lung cancer. Qual Life Res 2003; 12: 157-66.

9. Carlsen K, Jensen AB, Jacobsen E, Krasnik M, Johansen C. Psychosocial aspects of lung cancer. Lung Cancer 2005; 47: 293-300.

10. Degner LFSJ. Symptom distress in newly diagnosed ambulatory care patients and as a predictor of survival in lung cancer. J Pain Symptom Manage 1995; 10: 423-31.

11. Tanaka K, Akechi T, Okuyama T, Nishiwaki Y, Uchitomi Y. Impact of dyspnea, pain, and fatigue on daily life activities in ambulatory patients with advanced lung cancer. J Pain Symptom Manage 2002; 23: 417-23.

12. O'Driscoll M, Corner J, Bailey C. The experience of breathlessness in lung cancer. Eur J Cancer Care 1999; 8: 37-43.

13. Grutters JP, Joore MA, Wiegman EM, et al. Health-related quality of life in patients surviving non-small cell lung cancer. Thorax 2010; 65: 903-7.

14. Jacot W, Colinet B, Bertrand D, et al. Quality of life and comorbidity score as prognostic determinants in non-small-cell lung cancer patients. Ann Oncol 2008; 19: 1458-64.

15. England R, Maddocks M, Manderson C, Wilcockn A. Factors influencing exercise performance in thoracic cancer. Respir Med 2012; 106: 294-9.

16. Schmitz KH, Holtzman J, Courneya KS, Masse LC, Duval S, Kane R. Controlled physical activity trials in cancer survivors: a systematic review and meta-analysis. Cancer Epidemiol Biomarkers Prev 2005; 14: 1588-95.

17. Sarna L. Fluctuations in physical function: adults with non-small cell lung cancer. J Adv Nurs 1993; 18: 714-24.

18. Luctkar-Flude M, Groll D, Woodend K, Tranmer J. Fatigue and physical activity in older patients with cancer: a six-month follow-up study. Oncol Nurs Forum 2009; 36: 194-202.

19. Jones LW, Eves ND, Haykowsky M, Freedland SJ, Mackey JR. Exercise intolerance in cancer and the role of exercise therapy to reverse dysfunction. Lancet Oncol 2009; 10: 598-605.

20. Loganathan RS, Stover DE, Shi W, Venkatraman E. Prevalence of COPD in women compared to men around the time of diagnosis of primary lung cancer. Chest 2006; 129: 1305-12

21. Jones LW. Peak oxygen consumption and long-term all-cause mortality in nonsmall cell lung cancer. Cancer 2010; 116: 4825-32.

22. Jones LW, Hornsby WE, Goetzinger A, et al. Prognostic significance of functional capacity and exercise behavior in patients with metastatic non-small cell lung cancer. Lung Cancer 2012; 76: 248-52.

23. Kasymjanova G, Correa JA, Kreisman H. Prognostic value of the six-minute walk in advanced non-small cell lung cancer. J Thorac Oncol 2009; 4: 602-7.

24. Nakaya N, Saito-Nakaya K, Akechi T, et al. Negative psychological aspects and survival in lung cancer patients. Psychooncology 2008; 17: 466-73.

25. Shannon VR Role of pulmonary rehabilitation in the management of patients with lung cancer. Curr Opin Pulm Med 2010; 16: 334-9.

26. Shin KY, Guo Y, Konzen B, Fu J, Yadav R, Bruera E. Inpatient cancer rehabilitation: the experience of a national comprehensive cancer center. Am J Phys Med Rehabil 2011; 90 (5 Suppl 1): S63-8.

27. Temel JS, Greer JA, Goldberg S, et al. A structured exercise program for patients with advanced non-small cell lung cancer. J Thorac Oncol 2009; 4: 595-601.

28. Salpeter SR, Malter DS, Luo EJ, Lin AY, Stuart B. Systematic review of cancer presentations with a median survival of six months or less. J Palliat Med 2012; 15: 175-85.

29. Belani CP, Wang W, Johnson DH, et al. Eastern Cooperative Oncology Group Phase III study of the Eastern Cooperative Oncology Group (ECOG 2597): induction chemotherapy followed by either standard thoracic radiotherapy or hyperfractionated accelerated radiotherapy for patients with unresectable stage IIIA and B nonsmall-cell lung cancer. J Clin Oncol 2005; 23: 3760-7.

30. Maltais F, LeBlane P, Whittorn F, et al. Oxidative enzyme activities of the vastuslateralis muscle and the functional status in patients with COPD. Thorax 2000, 55: 848-853.

31. Maltais F, Sullivan MJ, LeBlane P, et al. Altered expression of myosin heavy chain in the vastuslateralis muscle in patientswith COPD. Eur Respir J 1999, 13: 850-854

32. Jones LW, Eves ND, Mackey JR, et al. Safety and feasibility of cardiopulmonary exercise testing in patients with advancedcancer. Lung Cancer 2007; 55: 225-232.

33. Jones LW, Watson D, Herndon JE $2^{\text {nd }}$, et al. Peak oxygen consumption and long-term all-cause mortality in nonsmall cell lung cancer Cancer 2010; 116: 4825-32.

34. Jones LW, Hornsby WE, Goetzinger A. Prognostic significance of functional capacity and exercise behavior in patients with metastatic non-small cell lung cancer. Lung Cancer 2012; 76: 248-52.

35. Friedenreich CM, Orenstein MR. Physical activity and cancer prevention: etiologic evidence and biological mechanisms. J Nutr 2002; 132 (11 Suppl): 3456S-3464S.

36. Steindorf K, Friedenreich C, Linseisen J, et al. Physical activity and lung cancer risk in the European Prospective Investigation into Cancer and Nutrition Cohort. Int J Cancer 2006; 119: 2389-2397.

37. International Agency for Research on Cancer: IARCHandbooks of Cancer Prevention, voI6, Weight Controland Physical Activity. Lyon, France: IARC; 2002.

38. Keogh JW, Macleod RD. Body composition, physical fitness, functional performance, quality of life, and fatigue benefits of exercise for prostate cancer patients: a systematic review. J Pain Symptom Manage 2012; 43: 96-110.

39. Denlinger CS, Engstrom PF. Colorectal cancer survivorship: movement matters. Cancer Prev Res (Phila) 2011; 4: 502-511. 
40. Granger CL, McDonald CF, Berney S, Chao C, Denehy L. Exercise intervention to improve exercise capacity and health related quality of life for patients with non-small cell lung cancer: a systematic review. Lung Cancer 2011; 72: 139e153.

41. Adamsen L, Stage M, Laursen J, Rorth M, Quist M. Exercise and relaxation intervention for patients with advanced lung cancer: a qualitative feasibility study. Scand J Med Sci Sports 2012; 22: 804-15.

42. Headley JA, Ownby KK, John LD. The effect of seated exercise on fatigue and quality of life in women with advanced breast cancer. Oncol Nurs Forum 2004; 31: $977 \mathrm{e} 983$.

43. Oldervoll LM, Loge JH, Lydersen S, et al. Physical exercise for cancer patients with advanced disease: a randomized controlled trial. Oncologist 2011; 16: 1649e1657.

44. Morris GS, Gallagher GH, Baxter MF, et al. Pulmonary Rehabilitation improves functional status in oncology patients. Arch Phys Med Rehabil 2009; 90: 837-41.

45. Cheville AL, Kollasch J, Vandenberg J, et al. HomeBased Exercise Program to Improve Function, Fatigue, and Sleep Quality in Patients With Stage IV Lung and Colorectal Cancer: A Randomized Controlled Trial. $J$ Pain Symptom Manage 2013; 45: 811-21.

46. Temel JS, Greer JA, Goldberg S, et al. A structured exercise program for patients with advanced non-small cell lung cancer. J Thorac Oncol 2009; 4: 595-601.

47. Jones LW, Liang Y, Pituskin EN, et al. Effect of exercise training on peak oxygen consumption in patients with cancer: a meta-analysis. Oncologist 2011; 16: 112-20.

48. Marks LB, Yu X, Vujaskovic Z, Small W Jr, Folz R, Anscher MS. Radiation-induced lung injury. Semin Radiat Oncol 2003; 13: 333-45.

49. Bauerle O, Chrusch CA, Younes M. Mechanisms by whichCOPD affects exercise tolerance. Am J Respir Crit Care Med 1998; 157: 57-68.

50. Cramp F, Daniel J. Exercise for the management of cancer-related fatigue in adults. Cochrane Database Syst Rev 2008; (2): CD006145.

51. Adamsen L, Quist M, Midtgaard J, et al. The effect of a multidimensional exercise intervention on physical capacity, well-being and quality of life in cancer patients undergoing chemotherapy. Support Care Cancer 2006; 14: 116-27.

52. Quist M, Rorth M, Langer S, et al. Safety and feasibility of a combined exercise intervention fo inoperable lung cancer patients undergoing chemotherapy: a pilot study. Lung Cancer 2012; 75: 203e208.

53. Riesenberg H, Lübbe AS. In-patient rehabilitation of lung cancer patients - a prospective study. Support Care Cancer 2010; 18: 877-82.

54. Glattki GP, Manika K, Sichletidis L, Alexe G, Brenke $\mathrm{R}$, Spyratos D. Pulmonary rehabilitation in non-small cell lung cancer patients after completion of treatment. Am J Clin Oncol 2012 35: 120-5.

55. Hwang CL, Yu CJ, Shih JY, Yang PC, Wu YT. Effects of exercise training on exercise capacity in patients with non-small cell lung cancer receiving targeted therapy. Support Care Cancer 2012; 20: 3169-77.

56. Pasqua F, D'Angelillo R, Mattei F, et al . Pulmonary rehabilitation following radical chemo-radiation in locally advanced non surgical NSCLC: Preliminary evidences. Lung Cancer 2012; 76: 258-9.

57. Ferguson MK, Lehman AG, Bolliger CT, Brunelli A. The role of diffusing capacity and exercise tests. Thorac Surg Clin.2008; 18: 9-17.

58. Ferguson MK, Vigneswaran WT. Diffusing capacity predicts morbidity after lung resection in patients without obstructive lung disease. Ann Thorac Surg 2008; 85: 1158-1165.

59. Brunelli A, Belardinelli R, Refai M. Peak oxygen consumption during cardiopulmonary exercise test im- proves risk stratification in candidates to major lung resection. Chest 2009; 135: 1260-7.

60. Bobbio A, Chetta A, Internullo E, et al. Exercise capacity assessment in patients undergoing lung resection. Eur J Cardiothorac Surg 2009; 35: 419-22.

61. Benzo R, Kelley GA, Recchi L, Hofman A, Sciurba F. Complications of lung resection and exercise capacity: a meta-analysis. Respir Med 2007; 101: 1790-7.

62. Brunelli A, Charloux A, Bolliger CT, et al. European Respiratory Society and European Society of Thoracic Surgeons joint task force on fitness for radical therapy. ERS/ESTS clinical guidelines on fitness for radical therapy in lung cancer patients (surgery and chemo-radiotherapy). Eur Respir J 2009; 34: 17-41.

63. Pompili C, Salati M, Refai M, et al. Preoperative quality of life predicts survival following pulmonary resection in stage I non-small-cell lung cancer. Eur J Cardiothorac Surg 2013; 43: 905-10.

64. American Thoracic Society; American College of Chest Physicians: ATS/ACCP Statement on cardiopulmonary exercise testing. Am J Respir Crit Care Med 2003; 167: 211-277.

65. Jones LW, Eves ND, Haykowsky M, et al. Cardiorespiratory exercise testing in clinical oncology research: systematic review and practice recommendations. Lancet Oncol 2008; 9: 757-765.

66. Brunelli A, Belardinelli R, Refai M, et al. Peak oxygen consumption during cardiopulmonary exercise test improves risk stratification in candidates to major lung resection. Chest 2009; 135: 1260-7.

67. Brunelli A, Belardinelli R, Pompili C, et al. Minute ventilation-to-carbon dioxide output $\left(\mathrm{VE} / \mathrm{VCO}_{2}\right)$ slope is the strongest predictor of respiratory complications and death after pulmonary resection. Ann Thorac Surg 2012; 93: 1802-6.

68. Brunelli A, Pompili C, Belardinelli R. Beyond peak $\mathrm{VO}_{2}$ : ventilatory inefficiency $\left(\mathrm{VE} / \mathrm{VCO}_{2}\right.$ slope $)$ measured during cardiopulmonary exercise test to refine risk stratification in lung resection candidates. Eur $J$ Cardiothorac Surg 2010; 38: 19-20.

69. Brunelli A, Refai M, Xiumé F, et al. Performance at symptom-limited stair-climbing test is associated with increased cardiopulmonary complications, mortality, and costs after major lung resection. Ann Thorac Surg 2008; 86: 240-248.

70. Brunelli A. Stair-climbing test and lung surgery. Back to the future. Respiration 2008; 75: 372-3.

71. Brunelli A, Xiumé F, Refai M, et al. Peak oxygen consumption measured during the stair-climbing test in lung resection candidates. Respiration 2010; 80: 207-11.

72. Brunelli A, Pompili C, Berardi R, et al. Performance at preoperative stair-climbing test is associated with prognosis after pulmonary resection in stage I nonsmall cell lung cancer. Ann Thorac Surg 2012; 93: 1796-800.

73. Baser S, Shannon VR, Eapen GA, et al. Pulmonary dysfunction as a major cause of inoperability among patients with non-small-cell lung cancer. Clin Lung Cancer 2006; 7: 344-9.

74. Nagamatsu Y, Maeshiro K, Kimura NY, et al. Longterm recovery of exercise capacity and pulmonary function afterlobectomy. Thorac Cardiovasc Surg 2007: 134: 1273-1278.

75. Wang JS, Abboud RT, Wang Effect of lung resection on exercise capacity and on carbon monoxide diffusing capacity during exercise. Chest 2006; 129: 863-72.

76. Bozcuk H, Martin C. Lung Cancer. Does treatment delay affect survival in non-small cell lung cancer? A retrospective analysis from a single UK centre. Lung Cancer 2001; 34: 243-52.

77. Jones LW, Peddle CJ, Eves ND, et al. Effects of presurgical exercise training on cardiorespiratory fitness among 
patients undergoing thoracic surgery for malignant lung lesions. Cancer 2007; 110: 590-598.

78. Peddle CJ, Jones LW, Eves ND, et al. Effects of presurgical exercise training on quality of life in patients undergoing lung resection for suspected malignancy: a pilot study. Cancer Nurs 2009; 32: 158-65.

79. Bobbio A, Chetta A, Ampollini L, et al. Preoperative pulmonary rehabilitation in patients undergoing lung resection for non-small cell lung cancer. Eur J Cardiothorac Surg 2008; 33: 95-8.

80. Morano MT, Araújo AS, Nascimento FB, et al. Preoperative pulmonary rehabilitation versus chest physical therapy in patients undergoing lung cancer resection: a pilot randomized clinical trial. Arch Phys Med Rehabil 2013; 94: 53-8.

81. Cesario A, Ferri L, Galetta D, et al. Preoperative PRand surgery for lung cancer. Lung Cancer 2007; 57: 118-9.

82. Saltin B, Blomqvist G, Mitehell JH, et al. Response to exercise after bed rest and after training. Circulation 1968; 38 (5 Suppl): VIII-VII78.
83. McGuire DK, Levine BD, Williamson JW, et al. A 30year follow-up of the Dallas Bedrest and Training Study: I. Effect of age on the cardiovascular response to exercise. Circulation 2001; 104: 1350-1357.

84. McGuire DK, Levine BD, Williamson JW, et al. A 30year follow-up of the Dallas Bedrest and Training Study: II. Effect of age on cardiovascular adaptation to exercise training. Circulation 2001; 104: 1358-1366.

85. Spruit MA, Janssen PP, Willemnsen SC, et al. Exercise capacity before and after an 8 -week multidiseiplinary inpatient rehabilitation program in lung eaneer patients: a pilot study. Lung Cancer 2006; 52: 257-260.

86. Cesario A, Ferri L, GaIetta D, et al. Post-operative respiratory rehabilitation after lung resection for non-small cell lung cancer. Lung Cancer 2007; 57:175-80.

87. Jones LW, Eves ND, Peterson BL, et al. Safety and feasibility of aerobic training on cardiopulmonary function and quality of life in postsurgical non-small cell lung cancer patients: a pilot study. Cancer 2008; 113: 3430-3439.

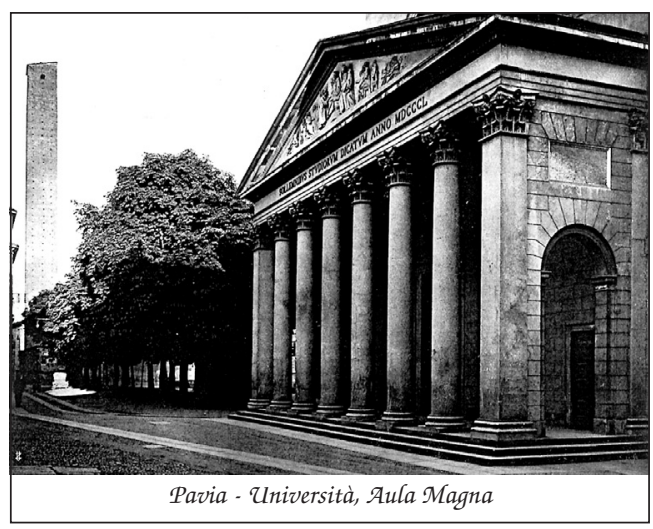

